\title{
Treatment of Early Syphilis with Erythromycin
}

\author{
ASTON B. GREAVES, M.D.
}

W ITH THE INCREASE in reactions to penicillin $(1,2)$ the necessity for evaluating other antibotics in syphilotherapy has become compelling. Among the newer and more promising antibacterial substances being assayed as penicillin substitutes are erythromycin, carbomycin (Magnamycin), and chloramphenicol $(3-10)$.

An investigation of these antibiotics in the treatment of syphilis was conducted by the venereal disease control program of the District of Columbia Department of Public Health, under the supervision of the Venereal Disease Branch of the Public Health Service Communicable Disease Center. Our contribution to this research was the treatment of 29 early syphilis patients with a total dosage of $10 \mathrm{gm}$. of propionyl erythromycin $(A)$.

\section{Materials and Methods}

Primary and secondary syphilitic patients attending the Northwest Central Clinic, Venereal Disease Control Program, District of Columbia Department of Public Health, were selected for this project. All had lesions darkfield positive for Treponema pallidum. Willingness to cooperate, basic intelligence, and stability of residence were the other deciding factors in choosing patients for the project. Those judged acceptable were immediately

Dr. Greaves is supervisory medical officer, venereal disease control program, District of Columbia Department of Public Health. Edward A. Thompson served as investigator for the project. given an initial dose of $2 \mathrm{gm}$. of propionyl erythromycin orally in the clinic followed by 1 capsule $(250 \mathrm{mg}$.) three times a day at each meal and at bedtime for 6 days and an additional $2 \mathrm{gm}$. in the clinic on the eighth day. This schedule insured that at least 4 gm. of the medication was taken under supervision. Dark-field examinations were repeated when the patients made their first return visit. Blood was drawn for serologic tests for syphilis each month for 6 months after treatment, then on the 9 th and 12th months. The genitalia, skin, mucosa, and anus were inspected each time blood was taken. The blood specimens were mailed directly to the Public Health Service Venereal Disease Research Laboratory at Chamblee, Ga., where VDRL, KRP, FTA, and tpcf-50 tests were performed on each specimen. A spinal fluid examination was made at the 12th month after treatment, or at the time of serologic or clinical relapse.

\section{Results}

Fifteen of the 29 patients in the study experienced no discomfort from treatment with propionyl erythromycin. Drug intolerance, when present, was referable to the gastrointestinal tract. Symptoms included diarrhea, nausea, and abdominal pain, occurring singly or in various combinations.

Repeat dark-field examinations were negative in most patients on the third or fourth day after treatment. However, T. pallidum disappeared from the lesions of four patients 2 days after therapy was instituted. 
Of the original 29 patients, 5 proved to be recalcitrant and were lost from the project. Three of the remaining 24 were treatment failures and four were reinfections.

\section{Treatment Failures}

Case 1 was diagnosed secondary syphilis with a chancre of the right labia majora and maculopapular syphilides involving the palms and soles on April 22, 1959. Dark-field examination from the labial lesion was positive. Pretreatment VDRL test was reactive to a dilution of 32 . The patient's titer decreased to 4 dils 2 months after therapy and then rose to 16 dils the following month. Examination at that time revealed dark-field positive moist lesions of the vulva.

Case 2 presented a chancre of the prepuce with syphilitic alopecia and maculopapular syphilides of the palms, soles, and scrotum on April 6, 1959. His initial serologic test was reactive to a dilution of 32 . On May 6, 1959, there was a reappearance of the former lesions, in addition to new lesions of the upper and lower extremities and the scrotum. On that same date the VDRL test was reactive $1: 16$.

Case 3 exhibited a chancre of the prepuce, palmar and plantar syphilides, and condyloma

\section{Post-treatment results of VDRL test in early syphilis patients treated with erythromycin}

\begin{tabular}{|c|c|c|c|c|c|}
\hline \multirow{2}{*}{$\begin{array}{l}\text { Stage of } \\
\text { syphilis }\end{array}$} & \multirow{2}{*}{$\begin{array}{c}\text { Pretreat- } \\
\text { ment } \\
\text { serology }\end{array}$} & \multicolumn{4}{|c|}{$\begin{array}{l}\text { Post-treatment results of VDRL } \\
\text { test, in dilutions }\end{array}$} \\
\hline & & $\begin{array}{c}3 \\
\text { months }\end{array}$ & $\begin{array}{c}6 \\
\text { months }\end{array}$ & $\begin{array}{c}9 \\
\text { months }\end{array}$ & $\begin{array}{c}12 \\
\text { months }\end{array}$ \\
\hline Secondary & $\begin{array}{r}64 \\
32 \\
32 \\
32 \\
16 \\
16 \\
16 \\
8\end{array}$ & $\begin{array}{r}4 \\
4 \\
2 \\
1 \\
2 \\
1 \\
\mathrm{~N} \\
16\end{array}$ & $\begin{array}{r}1 \\
2 \\
1 \\
\mathrm{WR}-0 \\
1 \\
\mathrm{WR} \\
\mathrm{WR}-0 \\
8\end{array}$ & $\begin{array}{r}1 \\
2 \\
1 \\
\mathrm{WR} \\
2 \\
\mathrm{WR} \\
\mathrm{WR}-0 \\
4\end{array}$ & WR \\
\hline Primary _..- & $\begin{array}{r}32 \\
16 \\
16 \\
4 \\
2 \\
1 \\
1 \\
\mathrm{WR}-0 \\
\mathrm{~N}\end{array}$ & $\begin{array}{r}\mathrm{N} \\
4 \\
\mathrm{~N} \\
\mathrm{WR}-0 \\
4 \\
1 \\
\mathrm{~N} \\
\mathrm{~N} \\
\mathrm{WR}-0\end{array}$ & $\begin{array}{r}\mathrm{N} \\
1 \\
\mathrm{~N} \\
\mathrm{WR}-0 \\
2 \\
1 \\
\mathrm{~N} \\
\mathrm{~N} \\
\mathrm{~N}\end{array}$ & $\begin{array}{r}\mathrm{N} \\
2 \\
\mathrm{~N} \\
\mathrm{~N} \\
2 \\
\mathrm{WR}-\mathbf{0} \\
\mathrm{N} \\
\mathrm{N} \\
\mathrm{N}\end{array}$ & $\mathbf{N}$ \\
\hline
\end{tabular}

Note: WR-weakly reactive; WR-0-weakly reactive to negative; $\mathrm{N}$-negative. lata of the prepuce and penis. His pretreatment serologic test was 16 dils on August 14, 1959. Two months later his titer decreased to 2 dils and then rose to 8 and 16 dils on November 17 and December 14, respectively. Physical examination on December 14 disclosed a reappearance of annular lesions of the scrotum.

\section{Reinfections}

Case 4 was diagnosed secondary syphilis on March 19, 1959. A dark-field positive chancre of the perianal area, patchy alopecia, thinning of the eyebrows, and palmar and facial syphilides were discovered. His blood serum was reactive to a dilution of 128 . His titer decreased to a dilution of 1 on July 19 and August 20 but rose to 4 dils on September 21. Examination at this time revealed a chancre of a hemorrhoidal skin tag.

Case 5 presented dual chancres of the prepuce on April 22, 1959. His pretreatment titer was 16 dils. He became seronegative on June 24 and remained so until October 21, when he developed a new lesion of the coronal sulcus. He was designated "contact to secondary syphilis."

Case 6 had a verified history of treatment for early syphilis. He was diagnosed "reinfection, secondary syphilis" on July 6,1959 , on the basis of moist lesions of the perianal area and papular syphilides of the palms and soles. His titer was 8 dils. On January 1, 1960, his titer dropped to 1 dil, rose to 2 dils on April 6, and was 8 dils on October 7. Examination on the last date revealed moist lesions of the perianal area.

Case 7 presented moist lesions of the vulva and maculopapular syphilides of the palms and face. Dark-field examination was positive. Her pretreatment titer was 32 dils on March 26, 1959. She became seronegative on July 28. On October 9 her titer rose to 8 dils. She was diagnosed as secondary syphilis in November 1959 at District of Columbia General Hospital, where she went for obstetrical care. A serologic test then was reactive $1: 16$. She delivered a syphilitic baby on November 13. A serologic test of the infant in December 1959 was 256 dils, and tests on January 5 and January 7, 1960, were 128 and 256 dils respectively. X-ray of the infant's long bones demonstrated syphilitic periostitis.

Patients who were treatment failures and 
reinfected patients were re-treated with penicillin therapy whenever practicable. The failure rate was 3 in 20 cases, or 15 percent. Seventeen patients completed the 1-year observation period.

The effectiveness of erythromycin against $T$. pallidum has previously been reported $(11,12)$. However, prolonged clinical and serologic observations are essential before final appraisal of any therapeutic agent is made. The results of the pretreatment VDRL tests on the 17 completed cases and of the quarterly serologic tests for 1 year after treatment are presented in the table. One patient was serologically negative prior to treatment; the blood of another was weakly reactive. Pretreatment serologic titers ranged from 0 to 64 . At the end of the first quarter five patients had become seronegative; an additional two were weakly reactive. After 6 months five were still seronegative while the serums of four were weakly reactive. At the ninth month six had lost measurable reagin; four others were weakly reactive. At the end of 1 year nine patients were seronegative, and one was weakly reactive. In addition, five patients showed a fourfold or more decrease in titer; another, less than a fourfold decrease; and one patient exhibited no change from his original titer. It was expected that of the nine patients who became seronegative, seven were syphilitics in the primary stage.

Of the five patients who lapsed from treatment two had seronegative primary syphilis and had remained seronegative for 5 months and 8 months, respectively, at the time of their last visit. One of the remaining three patients had lost measurable reagin 2 months after treatment, another showed a fourfold decrease in titer after the same period, and the third a fivefold decrease in titer at the end of 3 months.

Spinal fluid examination was performed on all 17 patients who completed treatment. All showed normal cell count, total protein, and nonreactive spinal fluid serology.

\section{Summary and Conclusion}

Twenty-nine dark-field positive primary and secondary syphilis patients were treated with a total dose of $10 \mathrm{gm}$. of propionyl erythromycin orally over an 8-day period. Serologic ex- aminations were performed each month for 6 months after completion of treatment and at the end of the 9 th and 12 th months. The genitalia, skin, mucosa, and anus were inspected each time a blood specimen was taken. Half of the patients tolerated the medication well. Drug intolerance, when present, was referable to the gastrointestinal tract. Treponema pallidum usually disappeared from lesions 3 or 4 days after treatment. Of the original 29 patients studied, 5 were recalcitrant and were lost from the project, 4 became reinfected, and 3 were treatment failures. The failure rate was 3 in 20 cases, or 15 percent. Seventeen patients completed the 1 year study. Nine of these became seronegative and the serum of another, weakly reactive.

It is concluded that propionyl erythromycin shows significant promise as an antisyphilitic drug, but a dosage of $10 \mathrm{gm}$. does not produce a cure comparable to that obtained with the best schedules of penicillin.

\section{REFERENCES}

(1) Welch, H., Lewis, C. N., Weinstein, H. I., and Boechman, B. B.: Severe reactions to antibiotics; a nationwide survey. Antibiot. Med. 4 : 800-813, December 1957.

(2) Taggart, S. R., and Greaves, A. B.: Incidence and emergency treatment of angioneurotic edema and anaphylactoid reactions from antibiotics. Med. Ann. D.C. 29 : 436-438, August 1960.

(3) Thomas, E. W. : Recent developments in the treatment of syphilis. New York J. Med. 56: 19181922, June 15, 1956.

(4) Baber, G. R.: Oxytetracycline intramuscular in the treatment of early syphilis. A.M.A. Arch. Dermat. $73:$ 489-492, May 1956.

(5) Montgomery, C. H., and Knox, J. M. : Antibiotics other than penicillin in the treatment of syphilis. New England J. Med. 261 : 277-280, Aug. $6,1959$.

(6) Montgomery, C. H., and Knox, J. M.: Erythromycin in the treatment of early syphilis. A preliminary report. A.M.A. Arch. Dermat. 80 : 205-209, August 1959.

(7) Vandow, J. E. : Recent advances in antimicrobial therapy. Part II. Antimicrobial therapy of syphilis. New York J. Med. 59: 4193-4202, Nov. 15, 1959.

(8) Olansky, S., and Garson, W.: The treatment of syphilis with antibiotics other than penicillin. A.M.A. Arch. Dermat. 77 : 648-650, June 1958.

(9) Rajam, R. V., and Sowmini, C. N.: Oral tetracy- 
cline in the prevention of prenatal syphilis. J. Indian M.A. 32 : 435-537, June 1, 1959.

(10) Buckinger, R. H., Hookings, C. E., and Garson, W.: A preliminary report on the effect of carbomycin in early syphilis. Antibiot. Med. 1: 100-103, February 1955.

(11) Turner, T. S., and Schaeffer, K.: The comparative effect of various antibiotics in experimental syphilis. Am. J. Syph. 38: 431-432, Feb. 14. 1959.

(12) King, A. J.: Drugs in the treatment of syphilis. Part II. Brit. M. J. 119 : 431-432, Feb. 14, 1959.

\section{EQUIPMENT REFERENCE}

(A) Ilosone. Eli Lilly and Co., Indianapolis, Ind.

\section{PUBLICATION ANNOUNCEMENTS}

\begin{abstract}
Address inquiries to publisher or sponsoring agency.
\end{abstract}

Personal Response and Social Organization in a Health Campaign: An evaluation of a mass $X$-ray survey in New York City. Research Series No. 9. By Charles A. Metzner and Gerald Gurin. 1960 ; 35 pages. Bureau of Public Health Economics, University of Michigan School of Public Health, Ann Arbor.

Diabetics Unknown. Public Affairs Pamphlet No. 312. By Groff Conklin. April 1961; 27 pages ; 25 cents. Public Affairs Pamphlets, 22 East 38th St., New York 16.

New Population Facts on Older Americans, 1960. 1961; 63 pages; single copies, Special Committee on Aging, Room 132, Senate Office Building ; multiple copies, 20 cents, Superintendent of Documents, U.S. Government Printing Office, Washington 25, D.C.

Style Manual for Biological Journals. Prepared by the Committee on Form and Style of the Conference of Biological Editors. $1960 ; 100$ pages; \$3. American Institute of Biological Sciences, 2000 P. St. NW., Washington 6, D.C.

Comparative Medicine in Transition. Proceedings of the First Institute on Veterinary Public Health Practice, 1958. 1960; School of Public Health, University of Michigan, Ann Arbor.

The Role of Nutrition in International Programs. July 1961; 12 pages. National Academy of Sciences-National Research Council, Food and Nutrition Board, 2101 Constitution Ave., Washington 25, D.C.
Eating Is Fun . . For Older People, Too. June 1961 ; 28 pages; single copy, 50 cents, reduction for larger quantities. Step Lively and Control Weight. May 1961; folder; single copy, 3 cents, reduction for large quantities. The American Dietetic Association, 620 North Michigan Ave., Chicago Ill.

Epidemiology in Nursing. Proceedings of the Workshop on Epidemiology in Nursing conducted at Catholic University of America, June 10-21, 1960. Edited by Marjorie J. Corrigan and Lucille E. Corcoran. $1961 ; 346$ pages; $\$ 4.25$. Catholic University of America Press, Washington 17, D.C.

Second Symposium of the International Association of Veterinary Food-Hygienists, Basel, Switzerland, May 15-21, 1960. 1961; 400 pages; $\$ 7$. Secretariat, International Association of Veterinary Food - Hygienists, 1, Sterrenbos, Utrecht, The Netherlands.

A List of Worthwhile Health Insurance Books. 1961; 31 pages. Health Insurance Institute, 488 Madison Ave., New York 22.

Youth Physical Fitness. Suggested Elements of a School-Centered Program. Part 1. Concept and Foundation. 1961; 14 pages. National Education Association, 1201 16th St., NW., Washington, D.C.

Job Futures for Girls in Biology. Leaflet 35. U.S. Department of Labor, Women's Bureau. 1961; 7 pages ; 5 cents. Superintendent of Documents, U.S. Government Printing Office, Washington 25, D.C.
Los Angeles County Mental Health Survey. $1961 ; 576$ pages plus tables, maps, and charts; $\$ 5.20$. Welfare Planning Council, 7331/2 South Hope St., Los Angeles 17.

\section{World Health Organization}

WHO publications may be obtained from the Columbia University Press, International Documents Service, 2960 Broadway, New York 27, N.Y.

Arthropod-Borne Viruses. Report of a study group. WHO Technical Series No. 219. 1961; $\$ 1$; Geneva.

Air Pollution. WHO Monograph Series No. 46. By K. Barker, et al. 1961 ; $\$ 8$; Geneva.

Ionizing Radiation and Health. WHO Public Health Papers No. 6. 1961 ; $\$ 1$; Geneva.

Basic Nursing Education Programmes. A guide to their planning. Public Health Papers No. 7. 1961; $\$ 1$; Genera.

Pharmaceutical Advertising. A survey of existing legislation. Vol. 12, No. 1 ; $1961 ; 53$ pages; 60 cents; Geneva.

Catalogue of WHO Publications, 1947-1960. 1961; 78 pages; Geneva.

Psychiatric Services and Architecture. WHO Public Health Papers No. 1. 1961 ; 60 cents ; Genera.

Epidemiological Methods in the Study of Mental Disorders. WHO Public Health Papers No. 2. 1961; $\$ 1$; Geneva.

Health Services in the USSR. Public Health Papers No. 3. 1961; 60 cents ; Geneva. 